\title{
PERAMALAN EKSPOR LUAR NEGERI BANTEN MENGGUNAKAN MODEL ARIMAX
}

\author{
Saeful Hidayat ${ }^{* 1}$, Nisrina Hakim ${ }^{2}$ \\ 1,2BPS Provinsi Banten \\ saefulh@bps.go.id ${ }^{* 1}$,nisrina@bps.go.id ${ }^{2}$
}

\begin{abstract}
Forecasting Banten exports is one of the important elements for formulating economic growth targets in the development planning document prepared by the Banten Provincial Government. The purpose of this study is to forecast exports by utilizing export data from the BPS and the United States manufacturing purchasing managers index (PMI) which is derived from the Institute of Supply Management (ISM). The results showed that the ARIMAX model has a very good forecasting ability. This is indicated by the MAPE value which reached 8.84 percent. However, forecasting accuracy will decrease as the forecasting time span increases.
\end{abstract}

Keyword: forecasting Banten exports, PMI ISM, ARIMAX model

\begin{abstract}
Abstrak
Peramalan ekspor Banten merupakan salah satu elemen penting untuk merumuskan target pertumbuhan ekonomi dalam dokumen perencanaan pembangunan yang disusun oleh Pemerintah Provinsi Banten. Tujuan penelitian ini adalah untuk melakukan peramalan ekspor dengan memanfaatkan data ekspor dari BPS dan PMI Manufaktur (manufacturing purchasing managers index) Amerika Serikat yang berasal dari Institute of Supply Management (ISM). Hasil penelitian menunjukkan bahwa model ARIMAX memiliki kemampuan peramalan yang sangat baik. Ini ditunjukkan oleh nilai MAPE yang mencapai 8,84 persen. Namun, akurasi peramalan akan mengalami penurunan seiring dengan bertambahnya rentang waktu peramalan.
\end{abstract}

Kata kunci: peramalan ekspor Banten, PMI ISM Amerika Serikat, model ARIMAX 
Jurnal Lebesgue : Jurnal Ilmiah Pendidikan Matematika, Matematika dan Statistika

Saeful Hidayat, Nisrina Hakim

Volume 2, No. 2, Agustus 2021 hal.204-213

DOI Artikel : 10.46306/lb.v2i2.75

\section{PENDAHULUAN}

Perdagangan internasional merupakan suatu aktivitas atau kegiatan perdagangan yang dilakukan oleh dua negera yang berbeda. Perdagangan internasional merupakan faktor penting dalam meningkatkan standar hidup dan menyediakan lapangan kerja, serta memungkinkan konsumen di berbagai negara untuk menikmati lebih banyak variasi barang dengan kualitas dan harga yang lebih bersaing. Oleh karena itu perdagangan internasional menjadi kunci bagi kebangkitan ekonomi global.

Sebagai salah provinsi yang menjadi bagian dari Indonesia, Banten juga melakukan perdagangan internasional. Malahan berdasarkan data bulan Januari 2014 sampai April 2021, kontribusi ekspor Banten terhadap ekspor Indonesia rata-rata mencapai 6 persen per bulan. Sementara perkembangan ekspor bulanannya, meskipun berfluktuasi namun cenderung meningkat hingga menjadi 1,17 miliar US\$.

Sayangnya, selama tahun 2019-2020 terjadi penurunan terhadap ekspor Banten. Penurunannya ini secara umum didorong oleh melemahnya permintaan dunia dan negaranegara mitra dagang utama Banten, seperti Amerika Serikat, ASEAN, Tiongkok, Uni Eropa, dan Jepang. Khusus tahun 2019, melemahnya permintaan dunia dan negara-negara mitra dagang Banten, dipengaruhi oleh perang dagang antara Amerika Serikat dan Tiongkok, memburuknya situasi Timur Tengah, dan Brexit tanpa kesepatakan perdagangan internasional. Adapun pada tahun 2020, terutama dipengaruhi oleh pandemi Covid-19 yang mulai melanda dunia sejak akhir tahun 2019.

Di sisi lain, hampir seluruh ekspor Banten merupakan produk industri pengolahan. Sementara lapangan usaha industri pengolahan mendominasi struktur perekonomian Banten, sehingga sangat mempengaruhi perkembangan kinerja ekonomi Banten. Dengan demikian, ada kebutuhan untuk meramalkan perkembangan ke ekspor Banten, sebagai dasar untuk penentuan target pertumbuhan ekonomi dalam dokumen perencanaan yang disusun oleh Pemerintah Provinsi Banten.

Sementara itu ketersediaan data ekspor yang beruntun secara periodik dalam periode bulanan oleh BPS, dapat dijadikan masukan pada model peramalan. Oleh karena itu, model peramalan time series ekspor dengan variabel univariat dipilih sebagai model yang dipergunakan dalam penelitian ini. Pertimbangannya, selain karena aspek kesederhanaan dalam model, juga terbukanya peluang untuk meningkatkan akurasi peramalan. Akurasi peramalan tersebut dapat ditingkatkan dengan memasukkan variabel eksogen ke dalam model time series. 
Jurnal Lebesgue : Jurnal Ilmiah Pendidikan Matematika, Matematika dan Statistika

Saeful Hidayat, Nisrina Hakim

Volume 2, No. 2, Agustus 2021 hal.204-213

DOI Artikel : 10.46306/lb.v2i2.75

Dengan demikian, tujuan penelitian ini adalah untuk melakukan peramalan ekspor, dengan cara membentuk model peramalan ekspor. Adapun model yang dibentuk merupakan model ARIMAX, yakni model ARIMA yang diperluas dengan menambahkan variabel eksogen ke dalam model. Dalam hal ini, variabel eksogen yang dipilih adalah variabel yang mampu menggambarkan perkembangan kondisi ekonomi global dan negara-negara mitra dagang utama Banten.

Sementara itu laju pertumbuhan ekonomi sesungguhnya merupakan variabel yang paling tepat dalam menggambarkan perkembangan ekonomi suatu negara. Permasalahannya, tidak ada satu negara pun yang merilis pertumbuhan ekonomi bulanan. Selain itu, rilis pertumbuhan ekonomi periode triwulanan biasanya juga terlambat satu atau dua bulan setelah triwulan yang dimaksud.

Selain pertumbuhan ekonomi, nila kurs (exchange rate) bulanan sepertinya juga bisa digunakan untuk menggambarkan kondisi ekonomi bulanan suatu wilayah. Salah satu yang memanfaatkan nilai kurs sebagai variabel eksogen dalam model ARIMAX adalah VictorEdema and Essi (2016), ketika menyusun model peramalan ekspor non minyak Nigeria.

Selain pertumbuhan ekonomi dan nilai kurs, ada pula indikator ekonomi dini (leading indicator) yang dapat digunakan untuk menggambarkan kondisi ekonomi pada bulan mendatang. Salah satu yang menggunakan indikator ekonomi dini sebagai variabel eksogen dalam model ARIMAX adalah Kongcharoen dan Kruangpradit (2012), saat menyusun model peramalan ekspor Thailand. Dalam hal ini, indikator ekonomi dini yang digunakan adalah Composite Leading Indicator (MIE) dari Organisation for Economic Co-operation and Development (OECD).

\section{METODE PENELITIAN}

Penelitian ini menggunakan model ARIMAX (ARIMA with Exsogenous Variabel), yaitu hasil modifikasi model ARIMA dengan menambahkan variabel eksogen. Variabel eksogen adalah variabel yang dapat mempengaruhi variabel lain, tetapi tidak dipengaruhi oleh variabel lain dalam model tersebut. Variabel eksogen disebut juga sebagai variabel bebas. Adapun PMI Manufaktur (manufacturing purchasing managers index) Amerika Serikat dari Institute of Supply Management (ISM) digunakan sebagai variabel eksogen, sedangkan ekspor luar negeri Banten menjadi variabel time series-nya. 
Jurnal Lebesgue : Jurnal Ilmiah Pendidikan Matematika, Matematika dan Statistika

Saeful Hidayat, Nisrina Hakim

Volume 2, No. 2, Agustus 2021 hal.204-213

DOI Artikel : 10.46306/lb.v2i2.75

Pembentukan model ARIMAX diawali dengan melakukan pemodelan regresi time series. Jika error dari model regresi time series $\left(\varepsilon_{t}\right)$ telah memenuhi asumsi white noise, residual dari model regresi time series dimodelkan menggunakan model ARIMA.

Dalam penelitian ini, bentuk model $\operatorname{ARIMA}(p, d, q)(P, D, Q)^{S}$ untuk time series $x_{t}$ yang merupakan data atau variabel ekspor adalah sebagai berikut:

$\Phi_{P} B^{S} \phi_{p}(B)(1-B)^{d}\left(1-B^{S}\right)^{D} x_{t}=\mu+\theta_{q}(B) \Theta_{Q}\left(B^{S}\right) \varepsilon_{t}$

Dimana,

$\mu=$ intercep

$B=$ lag operator

$p$ dan $q=$ order autoregressive non musiman dan order moving average non musiman

$P$ dan $Q=$ order autoregressive musiman dan order moving average musiman

$d=$ order differencing non musiman

$D=$ order differencing musiman

$S=$ periode musiman, data bulanan $(S=12)$

$\phi_{p}(B)=$ komponen autoregressive non musiman

$\Phi_{P} B^{S}=$ komponen autoregressive musiman

$\theta_{q}(B)=$ komponen moving average non musiman

$\Theta_{Q}\left(B^{S}\right)=$ komponen moving average musiman

$(1-B)^{d}=$ differencing non musiman

$\left(1-B^{S}\right)^{D}=$ differencing non musiman

Tahapan yang dilakukan untuk memperoleh model ARIMA, antara lain: Pertama, pemeriksaan kestasioneran data dan identifikasi model. Pemeriksaan kestatisioneran data dilakukan dengan statistik Uji ADF (Augmented Dicky Fuller), sedangkan identifikasi model menggunakan Correlogram ACF dan PACF.

Kedua, pemilihan kandidat model terbaik, yang dilakukan berdasarkan signifikansi parameter dan nilai AIC (Akaike info criterion) yang terkecil. Uji signifikansi parameter dilakukan untuk memilih kandidat model terbaik. Adapun nilai AIC terkecil digunakan untuk menetapkan model terbaik, di antara kandidat model terbaik. 
Jurnal Lebesgue : Jurnal Ilmiah Pendidikan Matematika, Matematika dan Statistika

Saeful Hidayat, Nisrina Hakim

Volume 2, No. 2, Agustus 2021 hal.204-213

DOI Artikel : 10.46306/lb.v2i2.75

Ketiga, pemeriksaan diagnosa (diagnostic checking), yang dilakukan melalui uji asumsi sisaan white noise dari model tersebut, yakni uji autokorelasi sisaan dan uji heterokedastisitas sisaan. Jika Correlogram - $Q$ - statistics menunjukkan nilai probabilitas pada tiap lag yang lebih besar dari alpha $=5 \%$, maka sisaan tidak mempunyai autokerelasi sisaan. Adapun bila nilaiProb pada Correlogram Squared Residuals lebih besar dari alpha $=5 \%$ pada setiap lagnya, berarti variansi sisaan tidak bersifat heterokedastisitas.

Sementara itu PMI Manufaktur (manufacturing purchasing managers index) Amerika Serikat dari Institute of Supply Management (ISM), digunakan sebagai variabel eksogen. Pertimbangannya adalah karena Amerika Serikat masih merupakan negara dengan level ekonomi terbesar di dunia, sehingga perkembangan ekonominya sangat mempengaruhi kondisi ekonomi global. Selain itu, Amerika Serikat merupakan salah satu negara mitra dagang utama Banten.

PMI ISM sendiri adalah indikator ekonomi dini bulanan aktivitas ekonomi AS, yang dihitung berdasarkan survei kepada manajer pembelian pada lebih dari 300 perusahaan manufaktur. PMI ISM Ini merupakan indikator utama yang mampu mengukur keadaan ekonomi AS pada bulan mendatang.

Selanjutnya, setelah lolos dari pemeriksaan diagnosa, variabel eksogen $z_{t}$ (PMI ISM Amerika Serikat) dimasukkan ke dalam persamaan (1) sehingga diperoleh persamaan ARIMAX berikut:

$\Phi_{P} B^{S} \phi_{p}(B)(1-B)^{d}\left(1-B^{S}\right)^{D} x_{t}=\mu+(1-B)^{\delta} z_{t}+\theta_{q}(B) \Theta_{Q}\left(B^{S}\right) \varepsilon_{t}$

Dalam hal ini, pemodelan ARIMAX dilakukan pada model ARIMA terbaik. Setelah itu, diterapkan kegiatan tahapan kedua dan ketiga di atas pada model ARIMAX yang dihasilkan sehingga diperoleh model yang siap digunakan untuk peramalan. Sementara pengolahan datanya menggunakan aplikasi Eviews 8. Dengan demikian, model ARIMA dan ARIMAX-nya diestimasi dengan memakai metode Least Squares (NLS-ARMA).

Adapun pengukuran akurasi peramalan data testing dilakukan dengan menggunakan MAPE (Mean Absolute Percentage Error) yang dirumuskan sebagai berikut:

$M A P E=\frac{1}{V-T} \sum_{t=T+1}^{V}\left|\frac{F_{t}-A_{t}}{A_{t}} \times 100 \%\right|$ 
Jurnal Lebesgue : Jurnal Ilmiah Pendidikan Matematika, Matematika dan Statistika

Saeful Hidayat, Nisrina Hakim

Volume 2, No. 2, Agustus 2021 hal.204-213

DOI Artikel : 10.46306/lb.v2i2.75

Dengan $F_{t}$ merupakan hasil peramalan periode ke-t dan $A_{t}$ adalah nilai aktual periode ke-t. Berdasarkan MAPE, tingkat akurasi peramalan suatu model terbagi menjadi empat kelompok. Pertama, sangat baik (MAPE $\leq 10 \%)$. Kedua, baik (10\% < MAPE $\leq 20 \%)$. Ketiga, cukup baik $(20 \%<$ MAPE $\leq 50 \%)$. Keempat, buruk (MAPE > 50\%).

Data yang digunakan dalam penelitian ini adalah data ekspor bulanan Provinsi Banten selama periode Januari 2014 - April 2021 dari BPS Provinsi Banten dan data PMI ISM Amerika Serikat dari periode Januari yang diperoleh dari Investing.com (2021). Kedua data tersebut dibagi menjadi dua bagian, yakni periode Januari 2014 - Desember 2020 sebagai data training dalam pembentukan model peramalan. Sementara data periode Januari 2021 - April 2021 digunakan untuk testing peramalan.

\section{HASIL DAN PEMBAHASAN}

Gambar 1, menyajikan perkembangan ekspor Banten dan PMI Amerika serikat (selanjutnya disebut sebagai PMI) selama periode penelitian. Terlihat bahwa sebaran data keduanya tidak terfokus di sekitar nilai rata-rata dan varain dari data yang tidak konstan. Hal ini diperkuat dengan nilai statistik uji ADF (Tabel 1), yang masing-masing menghasilkan p-value lebih dari nilai kritis (alpha=0,05). Dengan demikian, kedua variabel tersebut tidak stasioner dalam level.

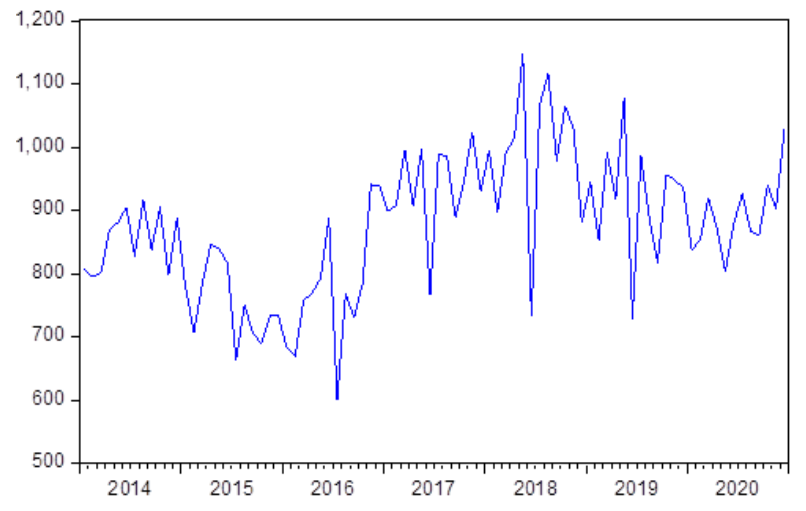

a. Ekspor Banten

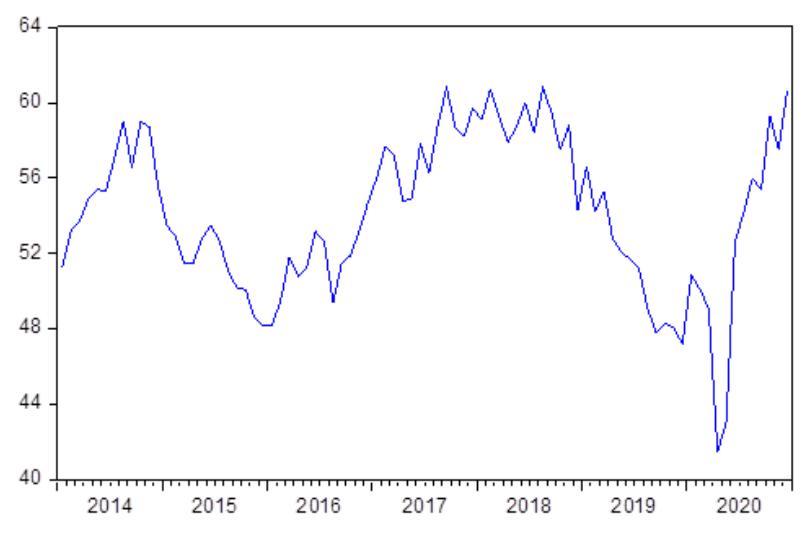

c. PMI ISM Amerika Serikat

Gambar 1. Perkembangan (a) ekspor Banten (juta US\$) dan (b) PMI ISM Amerika Serikat.

Untuk itu perlu dilakukan transformasi berupa pembedaan (difference). Berdasarkan Tabel 1, diperoleh informasi bahwa data ekspor dan PMI telah stasioner pada pembedaan pertama (first difference), karena memiliki p-value kurang dari 0,05. Berarti, hasil pembedaannya sudah dapat digunakan untuk mengestimasi model. 
Jurnal Lebesgue : Jurnal Ilmiah Pendidikan Matematika, Matematika dan Statistika

Saeful Hidayat, Nisrina Hakim

Volume 2, No. 2, Agustus 2021 hal.204-213

DOI Artikel : 10.46306/lb.v2i2.75

Tabel 1. Hasil Pengujian Augmented Dickey-Fuller (ADF) untuk Variabel Ekspor, Impor dan PMI Amerika Serikat.

\begin{tabular}{|c|c|c|}
\hline Variabel & Data Level & First Difference \\
\hline Ekspor & $-2,0763$ & $-11,1731$ \\
\hline PMI & $\begin{array}{c}(0,2547) \\
-2,218692\end{array}$ & $\begin{array}{c}(0,0001) \\
-9,417868\end{array}$ \\
\hline & $(0,2014)$ & $(0,0000)$ \\
\hline
\end{tabular}

Selanjutnya dilakukan identifikasi model ARIMA dengan menggunakan Correlogram ACF dan PACF dari first difference variabel ekspor. Berdasarkan plot ACF dan PACF diperoleh 7 (tujuh) alternatif model ARIMA, yang salah satunya akan ditetapkan sebagai model terbaik. Ketujuh model ARIMA tersebut adalah ARIMA $(1,1,0), \operatorname{ARIMA}(0,1,1), \operatorname{ARIMA}(0,1,2)$, ARIMA $(1,1,1), \operatorname{ARIMA}(1,1,2), \operatorname{ARIMA}(1,1,1)(0,0,1)^{12}$, dan ARIMA $(1,1,2)(0,0,1)^{12}$,

Tabel 2. Hasil estimasi model ARIMA untuk variabel dependen first difference ekspor

\begin{tabular}{|c|c|c|c|c|}
\hline Model & Koefisien & Std. Error & t-stat. & AIC \\
\hline 1. ARIMA $(1,1,0)$ & $-0,5925^{* * *}$ & 0,0910 & $-6,51$ & 12,00389 \\
\hline 2. ARIMA $(0,1,1)$ & $-0,7422 * * *$ & 0,0756 & $-9,82$ & 11,85024 \\
\hline 3. ARIMA $(0,1,2)$ & & & & 11,83024 \\
\hline $\operatorname{MA}(1)$ & $-0,9065^{* * *}$ & 0,1108 & $-8,18$ & \\
\hline $\operatorname{MA}(2)$ & 0,2087 & 0,1108 & 1,88 & \\
\hline 4. ARIMA $(1,1,1)$ & & & & 11,84364 \\
\hline $\operatorname{AR}(1)$ & $-0,2563$ & 0,1425 & $-1,80$ & \\
\hline $\operatorname{MA}(1)$ & $-0,6401 * * *$ & 0,1134 & $-5,64$ & \\
\hline 5. ARIMA $(1,1,2)$ & & & & 11,84096 \\
\hline $\operatorname{AR}(1)$ & $0,6459 * * *$ & 0,2161 & 2,99 & \\
\hline $\operatorname{MA}(1)$ & $-1,5608 * * *$ & 0,1799 & $-8,68$ & \\
\hline $\operatorname{MA}(2)$ & $0,7016^{* * *}$ & 0,1341 & 5,23 & \\
\hline 6. ARIMA $(1,1,1)$ & & & & 11,42051 \\
\hline $\operatorname{AR}(1)$ & $-0,3836 * *$ & 0,1492 & $-2,57$ & \\
\hline MA(1) & $-0,4328 * * *$ & 0,1456 & $-2,97$ & \\
\hline $\operatorname{SMA}(12)$ & $0,8877 * * *$ & 0,0255 & 34,79 & \\
\hline 7. ARIMA $(1,1,2)$ & & & & 11,43875 \\
\hline $\mathrm{AR}(1)$ & $-0,6064$ & 0,3096 & $-1,96$ & \\
\hline $\operatorname{MA}(1)$ & $-0,1853$ & 0,3388 & $-0,55$ & \\
\hline
\end{tabular}


Jurnal Lebesgue : Jurnal Ilmiah Pendidikan Matematika, Matematika dan Statistika

Saeful Hidayat, Nisrina Hakim

Volume 2, No. 2, Agustus 2021 hal.204-213

DOI Artikel : 10.46306/lb.v2i2.75

$\begin{array}{crrr}\operatorname{MA}(2) & -0,1995 & 0,2620 & -0,76 \\ \operatorname{SMA}(12) & 0,8913 * * * & 0,0252 & 35,33 \\ \text { Catatan : *** Sangat signifikan pada } \alpha=1 \% & \\ * * \text { Signifikan pada } \alpha=5 \% & \end{array}$

Sumber : Print out Eviews model ARIMA (data diolah penulis)

Pemilihan model ARIMA dilakukan berdasarkan signifikansi parameter estimasi dan nilai AIC yang terkecil. Dengan menggunakan alpha $=5 \%$, diperoleh 4 (empat) model ARIMA yaitu $(1,1,0)$, ARIMA $(0,1,1)$, ARIMA $(1,1,2)$, dan ARIMA $(1,1,1)(0,0,1)^{12}$ sebagai kandidat model terbaik. Di antara keempat model tersebut, model $(1,1,1)(0,0,1)^{12}$ menjadi model terbaik karena memiliki nilai AIC terkecil. Model ARIMA $(1,1,1)(0,0,1)^{12}$ yang terbaik ini memiliki spesifikasi order non musiman AR sebesar 1, order non musiman MA sebanyak 1 dan orde musiman MA pada periode 12 sebesar 1 pula.

Selanjutnya dilakukan pemeriksaan plot residual pada model ARIMA $(1,1,1)(0,0,1)^{12}$, dengan menggunakan Correlogram - Q - statistics dan Correlogram Squared Residuals. Berdasarkan plot ACF dan PACF yang tidak signifikan pada kedua Correlogram tersebut, dapat disimpulkan bahwa residual model ARIMA $(1,1,1)(0,0,1)^{12}$ sudah bersifat white noise. Dengan demikian, model ARIMA-nya memang model yang terbaik.

Tabel 3. Hasil estimasi model ARIMAX untuk variabel dependen first difference ekspor

\begin{tabular}{lrrc}
\hline \multicolumn{1}{c}{ Model } & Koefisien & Std. Error & t-stat. \\
\hline D(PMI(-1)) & $8,0985^{* * *}$ & 2,6130 & 3,10 \\
AR(1) & $-0,3280^{* *}$ & 0,1394 & $-2,35$ \\
MA(1) & $-0,6305^{* * *}$ & 0,1213 & $-5,20$ \\
SMA(12) & $0,8822^{* * *}$ & 0,0279 & 3,16 \\
\hline Adjusted R & 0,66878 & & \\
AIC & 11,34824 & & \\
Stat. Jarque-Bera (Normality & 0,06038 & & \\
Prob. Jarque-Bera (Normality & 0,97026 & & \\
\hline
\end{tabular}

Catatan : *** Sangat signifikan pada $\alpha=1 \%$

** Signifikan pada $\alpha=5 \%$

* Signifikan pada $\alpha=10 \%$

Sumber : Print out Eviews model ARIMAX (data diolah penulis)

Tahap terakhir dari pembentukan model adalah pemodelan ARIMAX. Pemodelan ARIMAX ini dilakukan terhadap model ARIMA $(1,1,1)(0,0,1)^{12}$, yakni dengan menambahkan variabel eksogen yaitu PMI. Berdasarkan Tabel 2, model ARIMAX yang dihasilkannya adalah: 
Jurnal Lebesgue : Jurnal Ilmiah Pendidikan Matematika, Matematika dan Statistika

Saeful Hidayat, Nisrina Hakim

Volume 2, No. 2, Agustus 2021 hal.204-213

DOI Artikel : 10.46306/lb.v2i2.75

$x_{t}=0,6720 x_{t-1}+0,3280 x_{t-2}+0,6305 \varepsilon_{t-1}-0,8822 \varepsilon_{t-12}-0,5562 \varepsilon_{t-13}+8,0985\left(z_{t-1}-z_{t-2}\right)$

Dengan demikian, ekspor periode bulan lalu dan dua bulan sebelumnya berpengaruh positif terhadap ekspor periode berjalan. Selain itu, perkembangan ekonomi Amerika Serikat yang terjadi pada bulan sebelumnya, baik akselerasi maupun perlambatan pertumbuhan ataupun kontraksi ekonomi, mempengaruhi ekspor pada bulan berjalan. Adapun sisaan atau kekurangakuratan peramalan periode satu bulan, dua belas bulan dan tiga belas bulan sebelumnya, menjadi faktor koreksi bagi peramalan ekspor bulan berjalan.

Sementara itu hasil pemeriksaan plot residual dengan menggunakan Correlogram - $Q$ statistics dan Correlogram Squared Residuals menunjukkan plot ACF dan PACF yang tidak signifikan atau white noise. Dengan demikian, model ARIMAX yang disajikan pada persamaan 4 di atas, bisa langsung digunakan untuk peramalan.

Selanjutnya dilakukan peramalan model ARIMAX pada data testing. Berdasarkan Tabel 4, diperoleh nilai MAPE sebesar 8,84 persen. Berarti, tingkat akurasi secara keseluruhan selama periode Januari 2021-April 2021 sudah sangat baik. Namun demikian, tingkat akurasi peramalan mengalami penurunan seiring dengan bertambah panjangnya rentang waktu peramalan. Ada kemungkinan hal ini disebabkan oleh masih sedikitnya jumlah variabel eksogen yang dimasukkan ke dalam model.

Tabel 4. Hasil peramalan ekspor dengan model ARIMAX

\begin{tabular}{|c|c|c|c|}
\hline Periode & Ekspor & Ramalan Ekspor & Akurasi (Persen) \\
\hline Januari 2021 & $\begin{array}{c}\text { Altand } \\
928\end{array}$ & 960,33 & 3,48 \\
\hline Februari 2021 & 979 & 944,13 & 3,56 \\
\hline Maret 2021 & 1106 & 961,14 & 13,10 \\
\hline April 2021 & 1171 & 992,72 & 15,22 \\
\hline \multicolumn{3}{|c|}{ MAPE } & 8,84 \\
\hline
\end{tabular}

Sumber : Hasil Peramalan Eviews model ARIMAX (data diolah penulis)

\section{KESIMPULAN}

Berdasarkan hasil dan pembahasan dapat disimpulkan bahwa model ARIMAX yang diperoleh telah memiliki kemampuan peramalan yang sangat baik. Hal ini ditunjukkan oleh nilai MAPE untuk data testing yang mencapai 8,84 persen. Namun, tingkat akurasi peramalan akan mengalami penurunan seiring dengan bertambah panjangnya rentang waktu peramalan. 
Jurnal Lebesgue : Jurnal Ilmiah Pendidikan Matematika, Matematika dan Statistika

Saeful Hidayat, Nisrina Hakim

Volume 2, No. 2, Agustus 2021 hal.204-213

DOI Artikel : 10.46306/lb.v2i2.75

Penurunan tingkat akurasi ini kemungkinan disebabkan oleh masih sedikitnya jumlah variabel eksogen yang dimasukkan ke dalam model. Oleh karena itu, pada penelitian-penelitian berikutnya dapat pula ditambahkan variabel eksogen lainnya guna meningkatkan akurasi peramalan. Salah satu variabel yang eksogen yang dapat ditambahkan adalah nilai kurs.

\section{DAFTAR PUSTAKA}

Agung, I Gusti Ngurah. 2009. Time Series Data Analysis Using Eviews. Singapore: John Wiley \& Sons (Asia) Pte Ltd.

Gujarati, Damodar N. 2004. Basic Economectrics, 4th Edition. New York: The McGrawHill Companies Inc.

Jantarakolica, T. and P. Chalermsook. 2012. Test Forecast Performance using Leading Indicator: A Case Study of Thai Export: Working paper, Thammasat University, Thailand.

Kongchareon, C. and Kruangpradit, T. 2013. Autoregressive Integrated Moving Average with Explanatory Variable (ARIMAX) Model for Thailand Export: Working paper, Thammasat University, Thailand.

Investing.com. 2021. "PMI Manufaktur ISM Amerika Serikat", https://id.investing.com/economic-calendar/ism-manufacturing-pmi-173, diakses pada tanggal 10 Juni 2021 pukul 11.05 WIB.

Victor-Edema, U. A. and Isaac D.E. 2016. Autoregressive Integrated Moving Average with Exogenous Variable (ARIMAX) Model for Nigerian Non Oil Export: European Journal of Bussines and Management, Vol. 8, No. 36. 